\title{
Special thanks to the Founding Editor of the Journal
}

\author{
Pierre Dutilleul • Ashis SenGupta
}

Published online: 10 June 2012

(C) Springer Science+Business Media, LLC 2012

In his December 2011 editorial, Professor Ganapati P. Patil, Founding Editor of Environmental and Ecological Statistics (EEST hereafter), had a "look back with a forward look," after some 20 years devoted to founding and editing the Journal. Very interestingly, this editorial was titled "Thank you all for the timely Journal we have," which inspired the present "Special thanks" editorial by the new Editors-in-Chief a few months later.

Indeed, we have inherited from Prof. Patil the challenge to take EEST forward, after a remarkable era guided by the Founding Editor. At a time when most research in statistical theory preceded applications, Prof. Patil's ingenuity and foresight led to the birth of EEST - a journal that would, and did, focus on real-life issues in the environmental sciences and ecology, and where statistical theories have been showcased to solve these issues. The trinity of knowledge from Ecological, Environmental and Statistical Sciences enhanced EEST as a very popular venue for the propagation of such interdisciplinary research. We express our deepest admiration and most sincere appreciation to Prof. Patil for having led EEST thus far. We profusely thank the departing Associate Editors, and heartily welcome the returning and new ones, while extending our thanks to the Reviewers for their time and efforts in assessing the scholarly content of EEST submissions.

In a later editorial, our authors and readers will be made aware of the visions and missions that we have in our endeavour to further promote excellence of EEST. While we will continue with the tradition of presenting timely, multi- and interdisciplinary

P. Dutilleul $(\varangle)$

McGill University, Montreal, QC, Canada

e-mail: pierre.dutilleul@mcgill.ca

A. SenGupta ( $\square)$

Indian Statistical Institute, Kolkata, India

e-mail: amsseng@gmail.com 
research to enhance statistical methods and theory for the analysis of real-life data in the environmental sciences and ecology, we feel that EEST may be enriched in a number of new directions. Details will appear shortly.

In all cases, we look forward to the continuing encouragement and scholarly submissions from our readers and authors, and we will combine our efforts to make of this, and the next years, the beginning of a new era of success for EEST, similar to the initial one under the Founding Editor. Thank you once again for everything, Prof. Patil.

Editors-in-Chief, EEST

June 2012 